\title{
Lysogeny and Colicinogeny in Escherichia coli
}

\author{
By J. PAPAVASSILIOU \\ Department of Microbiology, National University of Athens, \\ Goudi-Ampelokipi, Athens (6), Greece
}

(Received 29 December 1960)

\begin{abstract}
SUMMARY
One hundred and eighty-three strains of Escherichia coli were examined for lysogeny and colicinogeny: $\mathbf{4 0} \cdot 4 \%$ were neither lysogenic nor colicinogenic; $31 \cdot 1 \%$ were only colicinogenic; $13.1 \%$ were only lysogenic; $15.2 \%$ were lysogenic and colicinogenic. Though the detection of lysogeny could almost certainly be increased by using a greater number of sensitive indicator strains or by using more sensitive methods, the results of this study suggest: $(a)$ that lysogeny in $E$. coli is more frequent than found in earlier studies (Fredericq, 1952); (b) that lysogeny and colicinogeny are not correlated but occur independently in $E$. coli strains.
\end{abstract}

\section{INTRODUCTION}

Escherichia coli, Shigella spp. and some other groups of Enterobacteriaceae, which are often colicinogenic, were found to be rarely lysogenic by Fredericq (1952). On the other hand, salmonellas are commonly lysogenic but very seldom colicinogenic (Fredericq, 1952; Hamon, 1955; Papavassiliou \& Samaraki-Lyberopoulou, 1957; Papavassiliou, $1960 a$; Vassiliadis, Papavassiliou, Glaudot \& Sartiaux, 1960). In this study, 183 strains of Escherichia coli, comprising 115 freshly isolated strains of unknown serological type, 40 strains of serotype 111:B 4 pathogenic for infants, and 28 strains of serotype 70:B80 pathogenic for calves, were examined for both lysogeny and colicinogeny.

\section{METHODS}

Organisms examined. Of the strains examined 115 were freshly isolated from cultures made directly from human or animal faeces on MacConkey agar plates. These were examined for lysogeny and colicinogeny within a week of their isolation. Tests on freshly isolated strains were made before the organisms were identified; results with strains of the groups Klebsiella, Cloaca, Citrobacter and atypical strains are not reported here. Forty strains of Escherichia coli serotype $111: \mathrm{B} 4$, isolated in this laboratory from faeces of infants were also examined; these had been stored in ordinary media at room temperature for a few weeks. The remaining 28 strains belonged to $E$. coli serotype 70:B80 pathogenic for calves, and were received from Professor H. Fey (Faculty of Veterinary Medicine, University of Berne, Switzerland).

Indicator strains. Escherichia coli strain Row, obtained from Professor P. Fredericq (University of Liége, Belgium), was used in testing for colicinogeny. In tests for lysogeny, three strains of $E$. coli were used, namely, B, C and Y 20. All three were 
obtained from Professor P. Fredericq. Strain Y 20, a derivative of E. coli K 12 sensitive to phage $\lambda$, and previously used in tests for lysogeny with this phage (Fredericq \& Papavassiliou, unpublished), proved a less sensitive indicator for lysogeny in general than the first two. Strain B was a line of E. coli B, the strain used as indicator for the $\mathbf{T}$ series of phages; and strain $\mathrm{C}$ was a line of $\boldsymbol{E}$. coli $\mathrm{C}$, a strain used as indicator for the presence of phages in water.

When a strain was colicinogenic, it was tested for lysogeny with mutants of Escherichia coli B or C resistant to the colicine or colicines which it produced. For instance, Escherichia coli B/I (resistant to colicine I) was used in testing strains found to produce colicine I, and Escherichia coli $\mathrm{B} / \mathrm{E}+\mathrm{I}$ in testing strains which produced colicines $\mathbf{E}+\mathbf{I}$.

Media. Oxoid nutrient broth CM1 and Oxoid nutrient agar CM3 were used in this study. Nutrient broth was distributed in $5 \mathrm{ml}$. quantities. Nutrient agar plates contained about $40 \mathrm{ml}$. agar. The soft agar was prepared from Oxoid nutrient broth (5 g. agar in $1000 \mathrm{ml}$. broth).

Tests for colicinogeny. The double-layer method of Gratia (Fredericq, 1957) was used. Inocula from $\mathbf{2 4} \mathrm{hr}$. broth cultures of the strains to be tested were stabbed into nutrient agar with a straight wire, 8 strains/plate. After incubation for $48 \mathrm{hr}$., the macrocolonies which had developed were sterilized by chloroform vapour, and the indicator strain, Escherichia coli Row, was seeded over the whole surface by pouring $0.1 \mathrm{ml}$. of a $6 \mathrm{hr}$. broth culture diluted with $0.9 \mathrm{ml}$. broth and then mixed with 4-5 ml. melted soft agar cooled to below $50^{\circ}$ on to the plate. After incubation of the plates for $24 \mathrm{hr}$., clear zones of inhibition of the indicator could be seen round colicinogenic macrocolonies. The colicine which a strain produced was identified by testing it for activity against a series of mutants of $E$. coli strains Row or K 12 resistant to different known colicines (Fredericq, 1957).

Tests for lysogeny. The indicator strain was grown in $5 \mathrm{ml}$. broth for $4-5 \mathrm{hr}$. from an inoculum taken with a $5 \mathrm{~mm}$. loop from a $24 \mathrm{hr}$. broth culture. The indicator plate was prepared by pouring $0.1 \mathrm{ml}$. of this culture diluted with $0.9 \mathrm{ml}$. broth and then mixed with 4-5 ml. soft agar melted and cooled to below $50^{\circ}$ on to the agar plate. The plate was then dried by incubation at $37^{\circ}$ for $30-45 \mathrm{~min}$. with the lid open. Cultures of the strains to be tested grown for 3-4 hr. at $37^{\circ}$ in $5 \mathrm{ml}$. broth from inocula of $0.1 \mathrm{ml}$. taken from $24 \mathrm{hr}$. broth cultures were sterilized by chloroform (Fredericq, 1950). After standing on the bench for at least $30 \mathrm{~min}$., a $5 \mathrm{~mm}$. loopful was placed on the surface of the indicator plate, and the plate again dried for 30-45 min. with the lid open. The plates were examined after $20 \mathrm{hr}$. incubation at $37^{\circ}$.

With strains which were found to be non-colicinogenic, when plaques due to phage were present they were usually not subcultured. With colicinogenic strains, although colicine-resistant indicators were used, subcultures were made to confirm the presence of phage. No isolations or titrations of phages were made, however, as the object was to detect lysogenic strains, not to isolate new phages. 


\section{RESULTS}

Of the 183 strains examined, 24 $(13 \cdot 1 \%)$ were lysogenic, $57(31 \cdot 1 \%)$ only colicinogenic, $28(15 \cdot 2 \%)$ both lysogenic and colicinogenic, and $74(40 \cdot 4 \%)$ neither lysogenic nor colicinogenic (Table 1). The total percentage of lysogenic strains (regardless of colicinogeny) was $28.3 \%$; the percentage of colicinogenic strains was $46 \cdot 4 \%$. Table 1 also shows the origins of the strains.

Table 2 shows the types of colicines produced by the colicinogenic strains, and the numbers of these strains which were also lysogenic. No association was observed between lysogeny and the type of colicine produced.

Table 1. Lysogeny and colicinogeny of 183 strains of Escherichia coli and their origin

\begin{tabular}{|c|c|c|c|c|c|}
\hline Origin & Strains & Lysogenic & $\begin{array}{l}\text { Colicino- } \\
\text { genic }\end{array}$ & $\begin{array}{l}\text { Lysogenic } \\
\text { and colicino- } \\
\text { genic }\end{array}$ & $\begin{array}{l}\text { Neither lyso- } \\
\text { genic nor } \\
\text { colicinogenic }\end{array}$ \\
\hline Adult faeces & 94 & $\mathbf{9}$ & 29 & 13 & 43 \\
\hline $\begin{array}{l}\text { Serotype } 111: B 4 \\
\text { (infant faeces) }\end{array}$ & 40 & 6 & 12 & 14 & 8 \\
\hline $\begin{array}{l}\text { Animal faeces (rat } \\
\text { and mice) }\end{array}$ & 21 & 7 & 0 & $\mathbf{0}$ & 14 \\
\hline $\begin{array}{l}\text { Professor Fey's strains } \\
\text { (calf pathogenic) }\end{array}$ & 28 & 2 & 16 & $\mathbf{1}$ & 9 \\
\hline Total & 183 & 24 & 57 & 28 & 74 \\
\hline
\end{tabular}

Table 2. Occurrence of lysogeny in colicinogenic Escherichia coli

$\begin{array}{cccc}\text { Source or serotype } & \begin{array}{c}\text { Type of } \\ \text { colicine } \\ \text { produced }\end{array} & \begin{array}{c}\text { No. strains } \\ \text { examined }\end{array} & \begin{array}{c}\text { No. lysogenic } \\ \text { strains }\end{array} \\ \text { Adult faeces } & \mathbf{E} & 6 & 0 \\ & \mathbf{E}+\mathbf{I} & 10 & 3 \\ \text { Infant faeces } & \text { I } & 26 & 10 \\ \text { serotype 111:B4 } & \text { I } & 25 & 14 \\ \text { Calf pathogenic } & \text { E } & 1 & 0 \\ \text { serotype 70:B80 } & \text { V } & 3 & 1 \\ & \text { B } & 3 & 0 \\ & \text { E } & 1 & 0 \\ \text { Total } & \text { W } & 6 & 0 \\ & & 4 & 0 \\ & & 85 & 28\end{array}$

The specific serotypes of Escherichia coli 111:B4 (pathogenic for infants) and $E$. coli 70:B80 (pathogenic for calves) showed a particular incidence of lysogeny and colicinogeny. From the 40 strains of the serotype $111: B 4,26(65 \%)$ were colicinogenic, 25 produced colicine I, and one produced colicine E, and $20(50 \%)$ were lysogenic. From the 28 strains of the serotype 70:B80, $17(60.7 \%)$ were colicinogenic, but only $3(10.7 \%)$ were lysogenic. These results indicate that no direct relation existed between colicinogeny, lysogeny and pathogenicity, and also that pathogenic types could be subdivided into several types according to colicine- 
production, type of colicine produced, lysogeny and the combinations of these characteristics. This might be of epidemiological importance (Fredericq, BetzBareau \& Nicolle, 1956; Hamon \& Brault, 1959).

\section{DISCUSSION}

Lysogeny and colicinogeny in Escherichia coli are not associated, but occur independently. The present results are thus similar to those of Nagy (1959) who studied lysogeny and bacteriocinogeny in 100 strains of Bacillus megaterium. As he says ' no genetic correlation between the two lethal biosyntheses could be demonstrated and their occurrence was found to be essentially independent'. The incidence of colicinogeny reported in the present study $(46.4 \%)$ is higher than the incidence reported by Fredericq (1957), Hamon \& Brault (1959) and Papavassiliou (1959, $1960 c$ ) in other studies. This is possibly due to the examination of a number of strains of the serotypes $111: \mathrm{B} 4$ and $70: \mathrm{B} 80$, a high proportion of which were colicinogenic.

The incidences of lysogeny and colicinogeny found among the pathogenic serotypes cannot be considered as final: (i) the number of strains examined was small; (ii) at least some of these strains may possibly have been repeated isolations of the same strain. We have not yet typed strains from different laboratories all over the world, but the present results show clearly that even this small number of strains examined fall into several types with regard to their production of colicine, the type of colicine produced and lysogeny. By these characters strains isolated in Athens fall into 5 types and Professor Fey's strains into at least 7 types. The number of these types might possibly be increased by the examination of other characters, for instance sensitivity to colicines or the identification of phages produced.

The most important difference from previous results is the high incidence of lysogeny $(28.3 \%)$, which may have resulted from our use of different indicator strains (Fredericq, 1952). The incidence of lysogeny may have been even greater than actually observed, since the detection of lysogeny requires suitable indicator strains, and in addition some phages are sensitive to chloroform. In any case the incidence of lysogeny in Escherichia coli reported here is lower than the incidence reported for Salmonella (Fredericq, 1952) Proteus (Vieu, 1960) or Bacterium anitratum (Papavassiliou, 1960 b). In the present study, no difference in the incidence of lysogeny was observed between human and animal strains, but human strains are more frequently colicinogenic than animal strains (Papavassiliou, 1960c). $E$. coli $\mathrm{B}$ and $E$. coli $\mathrm{C}$ detect more lysogenic strains than $\boldsymbol{E}$. coli $\mathrm{Y} 20$. When the first two indicator strains were compared, while a number of lysogenic strains gave confluent lysis of $\mathbf{B}$ and only discrete plaques on $\mathbf{C}$, only one strain gave confluent lysis of $\mathrm{C}$ and only plaques on $\mathrm{B}$.

\section{REFERENCES}

FredericQ, P. (1950). Technique simple et rapide de culture et de conservation des entérobacteriophages. C.R. Soc. Biol., Paris, 144, 295.

FredericQ, P. (1952). Recherche des propriétés lysogènes et antibiotiques chez Salmonella. C.R. Soc. Biol., Paris, 146, 298.

FredericQ, P. (1957). Colicins. Annu. Rev. Microbiol. 11, 7. 
Fredericq, P., Betz-Bareau, M. \& Nicolne, P. (1956). Typage des souches d'Escherichia coli des gastroentérites infantiles par recherche de leurs propriétés colicinogènes. C.R. Soc. Biol., Paris, 150, 2039.

Fredericq, P. \& Papavassiliou, J. (1957). Croisement génétique de souches Escherichia coli marquées par production de colicine. I. C.R. Soc. Biol., Paris, 151, 1970.

Hamon, Y. (1955). Étude d'une colicine elaborée par une culture de $S$. typhimurium. Ann. Inst. Pasteur, 88, 193.

Hamon, Y. \& Brault, G. (1959). Recherche et identification de la propriété colicinogène parmi les différents lysotypes d'Escherichia coli pathogènes pour le nourisson. Interêt épidémiologique de cette étude. Ann. Inst. Pasteur, 96, 614.

NAGy, E. (1959). Lysogeny and bacteriocinogeny in B. megaterium. Acta microbiol. sci. hung. 6, 337.

Papavassiliou, J. (1959). Studies on the importance and biology of colicines produced by bacterial strains isolated from faeces. Thèse d'Agrégation Faculty of Medicine, University of Athens (in Greek).

Papavassiliou, J. (1960a). Colicinogénie et sensibilité aux colicines des Salmonella typhimurium isolées au Congo Belge. Ann. Soc. belge Méd. trop. 40, 369.

Papavassiliou, J. (1960b). Lysogeny of Bacterium anitratum. J. Bact. 80, 138.

Papavassiliou, J. $(1960 c)$. Colicinogénie et sensibilité aux colicines des Escherichiae d'origine humaine et animale. Arch. Inst. Pasteur Tunis, 37, 103.

Papavassiliou, J. \& Samaraki-Lyberopoulou, V. (1957). Production des colicines par Salmonella. Sensibilité des Salmonella à 5 colicines. Acta microbiol. hellen. 2, 325.

Vassiliadis, P., Papavassiliou, J., Glaudot, A. \& Sartiaux, P. (1960). Recherche des colicines chez Salmonella. (Étude sur 410 souches.) Ann. Inst. Pasteur, 99, 926.

VıEu, J. F. (1960). Lysogenéité et sensibilité à la colicine H de Proteus morgani. Ann. Inst. Pasteur, 98, 769. 